\title{
EDITORIAL
}

\section{To reg or not to reg: that is the question in COPD}

\author{
S. Baraldo and M. Saetta
}

C hronic obstructive pulmonary disease (COPD) is a major cause of death and disability worldwide, resulting in an economic and social burden that is in continuous progression [1]. In recent decades, significant improvements have been made to our understanding of COPD pathogenesis. In particular, it has been convincingly demonstrated that in patients with COPD, chronic inflammation is present not only in the lung but extends outside the organ, involving regional lymph nodes and systemic circulation [2-6]. Several cell lines, including macrophages, neutrophils and lymphocytes, participate in the inflammatory response that characterises COPD [7]. In particular, it has been proposed that CD8+ T-cells may be crucial in orchestrating the inflammatory response in this disease. Indeed, CD8+ Tlymphocytes infiltrate both central and peripheral airways [2, 3], lung parenchyma and pulmonary arteries [4]; not only are CD8 T-cells increased in all these compartments, they are also related to the degree of airflow limitation, suggesting that they may play an important role in the tissue damage and remodelling processes that determine the functional alterations in COPD.

Although nearly all smokers have some evidence of lung inflammation, only a minority of these will have an amplified response, and the mechanisms for this amplification are still poorly understood. It has been hypothesised that susceptibility to COPD may arise from a shift from the nonspecific innate response present in every smoker toward an adaptive immune response with features typical of autoimmune processes [8-10]. Indeed, in subjects with smoking-induced emphysema, the immune response has the characteristics of a type 1 response with production of interferon- $\gamma$ [10], which is crucial in the activation of macrophages, not only in response to viral and bacterial pathogens but also to auto-antigens. CD8+ T-cells also express CXCR3, a chemokine receptor that is known to be preferentially expressed on type 1 cells, and this expression is paralleled by a strong epithelial upregulation of its ligand CXCL10 [11]. The interaction between CXCL10 and CXCR3 induces the release of matrix metalloproteinase (MMP)-12 [12] from macrophages and, similarly, type 1 inflammation determines upregulation of other metalloproteinases, such as MMP-2 and -9 [13-15]. As MMPs are potent enzymes that degrade elastin and collagen, these data suggest a possible

Dept of Cardiologic, Thoracic and Vascular Sciences, Section of Respiratory Diseases, University of Padova, Padova, Italy.

STATEMENT OF INTEREST: None declared.

CORRESPONDENCE: M. Saetta, Università degli Studi di Padova, Dipartimento di Scienze Cardiologiche, Toraciche e Vascolari, Unità Operativa di Pneumologia, Via Giustiniani 3, 35128 Padova, Italy. Fax: 39 498213110. E-mail: marina.saetta@unipd.it mechanism through which T-helper cell type 1 lymphocytes can drive the progression of emphysema. All these diverse observations were elegantly unified in the recent paper by LEE et al. [10], demonstrating that the immune response in COPD has the features of an autoimmune process directed against elastin peptides.

In this issue of the European Respiratory Journal (ERJ), BARCELÓ et al. [16] add new details to our knowledge of the functional characteristics of T-lymphocytes in COPD. BARCELó et al. [16] analysed markers of activation (reduced CD28) and maturation (CD45RA/CD45R0) in lymphocytes isolated from bronchoalveolar lavage (BAL) and peripheral blood of smokers with COPD. By comparing the results to the appropriate groups of smoking and nonsmoking controls, they provide new insights into the mechanisms regulating the fate of lymphocytes in the lungs, in the context of either tobacco smoking or COPD. First, BARCELÓ et al. [16] found reduced CD28 expression (an index of activation) in BAL lymphocytes from all smokers, irrespective of the presence of COPD. This effect was not observed in peripheral blood T-lymphocytes, suggesting that a selective recruitment (or local activation) of T-lymphocytes may be a specific response to the lung injury induced by smoking. They also demonstrated an increased percentage of CD8+ Tlymphocytes expressing CD45RA (and a reduced expression of CD45R0) in patients with COPD as compared to smokers with normal lung function. As T-cell maturation involves sequential expression of CD45RA (naïve T-cells), CD45R0 (memory) and, again, CD45RA (effector/cytotoxic) [17, 18], these findings suggest that activated CD8+ T-cells only reach a state of final maturation in patients with COPD. These cells are highly cytotoxic, with a strong expression of intracytoplasmic perforin and granzyme, and therefore have a striking potential for determining tissue damage [19].

It is interesting to note that expansion of cells with these characteristics can also be found in other clinical conditions involving chronic activation of the immune system, such as viral infections, rheumatic and autoimmune diseases or tumours [19]. Finally, another important finding of the study by BARCELÓ et al. [16] was that a subset of T-regulatory cells (Treg; CD4+CD25+) was increased in smokers with normal lung function when compared to both never-smokers and smokers with COPD. Treg are a small subpopulation of lymphocytes that have been identified as key immunomodulators, which preserve the homeostasis of the immune system avoiding unnecessary reactions. Many different Treg subsets have been described, such as CD8+ Treg cells, natural killer cells and several different CD4+ Treg cell subsets, which include naturally occurring Treg cells (CD4+CD25+) and adaptive Treg cells [20]. 
The picture that emerges from these data is that, in all smokers, there is a certain degree of activation of T-lymphocytes; however, in those smokers who maintain normal lung function, despite considerable smoking consumption, this activation is restrained by the upregulation of Tregs. By contrast, in smokers who develop COPD and who are incapable of having an effective Treg response, the immune reaction progresses uncontrolled, involving the final differentiation of T-cells into the cytotoxic phenotype. These events will ultimately lead to the progressive lung tissue destruction that characterises emphysema. A lesson that can be learnt from this study is that although much of the ongoing research is focused on determining mechanisms of susceptibility to COPD, it is equally important to understand the mechanisms of resistance to COPD, which are activated in heavy smokers with normal lung function. By knowing the way in which these individuals manage to preserve their lung integrity, despite the unavoidable harm of cigarette smoke, we can learn a lot about the mechanisms of immune tolerance that are broken in COPD.

The study by BARCELÓ et al. [16] makes an important contribution; however, it is not without limitations. First, the authors did not fully characterise CD8+CD45RA+ cells to conclusively demonstrate that they represent the final stage of maturation. This would include characterisation of other functional markers, an aim that seems worth pursuing in future studies. In addition, they did not fully analyse the functional characteristics of Treg cells; for example, by examining the expression of transforming growth factor- $\beta$ besides that of interleukin-10. Finally, they analysed lymphocytes from BAL; it is presently unknown whether this would reflect the functional characteristics of $\mathrm{T}$ lymphocytes isolated from the lung tissue.

The data presented by BARCELO et al. [16] in this issue of the $E R J$ add new information to the debate on the role of lung inflammation in COPD. On the one hand, there is evidence that amplification of the inflammatory response is invariably associated with the establishment of airflow limitation in smokers [2$6]$, that this response progressively increases as the disease worsens [21, 22] and that it is required for the development of emphysema in some experimental models [23]. This seems to indicate that, instead of driving an effective immune response, T-lymphocytes are more likely to have detrimental effects, as suggested by BARCELÓ et al. [16]. On the other hand, it is equally plausible that T-lymphocytes may maintain their protective role in COPD, by driving an effective immune response which is essential to overcome infectious agents.

In conclusion, despite the increasing body of research on inflammatory mechanisms in chronic obstructive pulmonary disease, it is still uncertain whether the immune response is friend or foe to the patient. This takes us back to the concept that all our work, our efforts and our newly gained insights illuminate what is both our best friend and our worst foe: doubt. That, by opening the road to new paths, makes us move on.

\section{REFERENCES}

1 Rabe KF, Hurd S, Anzueto A, et al. Global strategy for the diagnosis, management, and prevention of chronic obstructive pulmonary disease: GOLD executive summary. Am J Respir Crit Care Med 2007; 176: 532-555.
2 O'Shaughnessy TC, Ansari TW, Barnes NC, Jeffery PK. Inflammation in bronchial biopsies of subjects with chronic bronchitis: inverse relationship of CD8+ T lymphocytes with FEV1. Am J Respir Crit Care Med 1997; 155: 852-857.

3 Saetta M, Di Stefano A, Turato G, et al. CD8+ Tlymphocytes in peripheral airways of smokers with chronic obstructive pulmonary disease. Am J Respir Crit Care Med 1998; 157: 822-826.

4 Saetta M, Baraldo S, Corbino L, et al. CD8+ve cells in the lungs of smokers with chronic obstructive pulmonary disease. Am J Respir Crit Care Med 1999; 160: 711-717.

5 Saetta M, Turato GB, Casoni GL, et al. Increased proportion of CD8+ T lymphocytes in the paratracheal lymph nodes of smokers with mild COPD. Sarcoidosis Vasc Lung Dis 2003; 20: 28-32.

6 Gan WQ, Man SF, Senthilselvan A, Sin DD. Association between chronic obstructive pulmonary disease and systemic inflammation: a systematic review and a metaanalysis. Thorax 2004; 59: 574-580.

7 Saetta M, Turato G, Maestrelli P, Mapp CE, Fabbri LM. Cellular and structural bases of chronic obstructive pulmonary disease. Am J Respir Crit Care Med 2001; 163: 1304-1309.

8 Cosio MG, Majo J, Cosio MG. Inflammation of the airways and lung parenchyma in COPD: role of T cells. Chest 2002; 121: Suppl. 5, 160S-165S.

9 Augusti A, MacNee W, Donaldson K, Cosio MG. Hypothesis: does COPD have an autoimmune component? Thorax 2003; 8: 832-884.

10 Lee SH, Goswami S, Grudo A, et al. Antielastin autoimmunity in tobacco smoking-induced emphysema. Nat Med 2007; 13: 567-569.

11 Saetta M, Mariani M, Panina-Bordignon $P$, et al. Increased expression of the chemokine receptor CXCR3 and its ligand CXCL10 in peripheral airways of smokers with chronic obstructive pulmonary disease. Am J Respir Crit Care Med 2002; 165: 1404-1409.

12 Grumelli S, Corry D, Song L, et al. An immune basis for lung parenchymal destruction in chronic obstructive pulmonary disease and emphysema. PLoS Med 2004; 1: 75-83.

13 Abraham M, Shapiro S, Karni A, Weiner HL, Miller A. Gelatinases (MMP-2 and MMP-9) are preferentially expressed by Th1 versus Th2 cells. J Neuroimmunol 2005; 163: 157-164.

14 Segura-Valdez L, Pardo A, Gaxiola M, Uhal BD, Becerril C, Selman M. Upregulation of gelatinases A and B, collagenases 1 and 2, and increased parenchymal cell death in COPD. Chest 2000; 117: 684-694.

15 Baraldo S, Bazzan E, Zanin ME, et al. Matrix metalloproteinase-2 protein in lung periphery is related to COPD progression. Chest 2007; 132: 1733-1740.

16 Barceló B, Pons J, Ferrer JM, Sauleda J, Fuster A, Agustí AGN. Phenotypic characterisation of T-lymphocytes in COPD: abnormal CD4+CD25+ regulatory T-lymphocyte response to tobacco smoking. Eur Respir J 2008; 31: 555-562.

17 Sallusto F, Geginat J, Lanzavecchia A. Central memory and effector memory $\mathrm{T}$ cell subsets: function, generation and maintenance. Annu Rev Immunol 2004; 22: 745-763.

18 Lanzavecchia A, Sallusto F. Understanding the generation and function of memory T cell subsets. Curr Opin Immunol 2005; 17: 326-332. 
19 Tarazona R, DelaRosa O, Alonso C, et al. Increased expression of NK cell markers on T lymphocytes in aging and chronic activation of the immune system reflects the accumulation of effector/senescent T cells. Mech Ageing Dev 2000; 121: 77-88.

20 van Oosterhout AJ, Bloksma N. Regulatory T-lymphocytes in asthma. Eur Respir J 2005; 26: 918-932.

21 Turato G, Zuin R, Miniati M, et al. Airway inflammation in severe chronic obstructive pulmonary disease: relationship with lung function and radiologic emphysema. Am J Respir Crit Care Med 2002; 166: 105-110.

22 Hogg JC, Chu F, Utokaparch S, et al. The nature of smallairway obstruction in chronic obstructive pulmonary disease. N Engl J Med 2004; 350: 2645-2653.

23 Maeno T, Houghton AM, Quintero PA, Grumelli S, Owen CA, Shapiro SD. CD8+ T cells are required for inflammation and destruction in cigarette smoke-induced emphysema in mice. J Immunol 2007; 178: 8090-8096. 